\title{
Presentation
}

\section{Thematic section: Psychology in the hospital context}

The inclusion of Psychology into the health context dates back to 1910s. In 1911, the American Psychological Association held discussions regarding the relationship between Psychology and medical education and practice (Winett, King, \& Altman, 1989). Traditionally, a clinical intervention model that encompassed Hospital Psychology has been adopted by this field, including in Brazil, where academic research on this topic began in the 1980s (Camon, 1984; Romano, 1990). However, changes in the understanding of the relationship between health and disease, with consequent changes in the proposals concerning the professional practice and role of psychologists, go beyond the individualized clinical care model. There have been changes since the organization of the field of Health Psychology in the 1970s (Matarazzo, 1980), along with the development of directly related fields, such as Pediatric Psychology (Crepaldi, Linhares, \& Perosa, 2006; Robert \& Steele, 2009), Psycho-oncology (Kazak et al., 2007), and Psychoneuroimmunology (Segerström, 2012; Slavich \& Cole, 2013). All of these fields depend on the interaction of knowledge derived from branches of Biology (Epigenetics and Neurosciences), Ecology (physical and social environments), and Health and Development (learning, behavior, physical, mental, and social well-being) from a Life Cycle Science perspective (Braveman \& Barclay, 2009; Dich et al., 2015; Miller, Chen, \& Parker, 2011; Shonkoff, Garner, The Committee on Psychosocial Aspects of Child and Family Health, Committee on Early Childhood, Adoption, and Dependent Care, \& Section on Developmental and Behavioral Pediatrics, 2012). They also depend on the Developmental Psychopathology (Rutter \& Sroufe, 2000), Health Psychology, Cognitive Science, Public Health, and Social Sciences, i.e., all those included in Human Development Sciences (Sameroff, 2010; Shonkoff et al., 2012).

Psychology professional practice in the medical context should therefore be interdisciplinary and multidisciplinary. Therefore, it changes the settings of work and research, which is carried out in waiting rooms, multiple occupancy patient rooms, outpatient clinic, emergency rooms, intensive care units, newborn nursery, and in individual rooms with rooming-in care, before and after invasive medical procedures, with patients of different ages on pre-consultation lists, as well as their families and caregivers and healthcare professionals (Boering \& Crepaldi, 2013; Crepaldi, Rabuske, \& Gabarra, 2006; Kazak, 2006).

Focusing on what was discussed and seeking to collaborate with the dissemination of knowledge and professional training and education in this field, this thematic section starts with a historical and conceptual article followed by discussions on developmental impacts resulting from early exposure to this stressful environment. Pain is one of the major stressors in this context, and it is directly addressed in two articles concerning pain management by healthcare professionals in a Neonatal Intensive Care Unit and also focusing on the field of Psychological Assessment in Psychology Health, discussing its association with personality traits. Following a timeline of situations involving the provision of care by psychologists in the hospital setting, the articles in this section concern studies on prenatal care with pregnant women at high risk and parents' coping strategies and fear of death of hospitalized children with cancer.

The introductory article, by Adriano Valério dos Santos Azevêdo and Maria Aparecida Crepaldi (Universidade Federal de Santa Catarina), presents the historical, conceptual, and practical aspects of psychology 
within a general hospital in the United States of America and in Brazil. It discusses psychological evaluation and intervention in the hospital considering the triad: patients, family, and healthcare team.

The second article, by Maria Beatriz Martins Linhares (School of Medicine of Ribeirão Preto, Universidade de São Paulo), presents theoretical-conceptual models about the impact of early stress on child development and health. However, it goes beyond the conceptual approach by presenting studies on Pediatric Psychology carried out in a public teaching hospital with hospitalized neonates and children whose clinical or medical treatment conditions involved highly stressful situations.

The article by Ana Cristina Barros da Cunha, José Paulo Pereira Junior, Cláudia Lúcia Vargas Caldeira and Vanessa Miranda Santos de Paula Carneiro (Universidade Federal do Rio de Janeiro) investigated the impact of the moment of diagnosis of fetal malformation on the mental health of pregnant women receiving prenatal care in the university Maternity Hospital (Universidade Federal do Rio de Janeiro).

Using a phenomenological approach, the fourth article in this section, by Sheila Maria Mazer-Gonçalves, Elizabeth Ranier Martins do Valle and Manoel Antônio dos Santos (Graduate Program in Psychology, Universidade de São Paulo - Ribeirão Preto), sought to understand the significance attributed by mothers whose children have completed cancer treatment to the death of other children undergoing cancer treatment at the hospital.

The fifth article, by Marina Kohlsdorf, Áderson Luiz Costa Junior and Felipe Diniz Marques (Universidade de Brasilia), is a cross-sectional study that addressed the effects of pre-consultation lists on the communicative behavior of caregivers and children. Having found recommendable and instructive results for the practice of psychologists in hospital settings, the authors showed that the procedure was associated with specific doubts of caregivers concerning dietary recommendations, coping with side effects, child development, biological aspects of cancer, and school activities. This study presented a low-cost procedure that can contribute to communication in pediatric settings.

In a study carried out with researchers from the Universidade Federal do Espírito Santo and the Pontifícia Universidade Católica de Campinas, Sandra Willéia Martins, Sônia Regina Fiorim Enumo and Kely Maria Pereira de Paula analyzed the influence of organizational factors on the engagement of healthcare professionals working in Neonatal Intensive Care Unit in effective pain management practices, supporting interventions aimed at humanized neonatal care.

Presenting another study on pain in the hospital context, this section ends with the article by Lucas de Francisco Carvalho, Ricardo Primi and Cláudio Garcia Capitão (Universidade São Francisco), which evaluates the personality characteristics of patients with chronic pain and compares them with those of patients without this condition. Contributing to the research in the field of Health Psychology, the analysis included the use of two scales that are adequate to the clinical context, providing relevant information to professionals in this field.

These seven articles illustrate the possibilities of carrying out studies in the hospital context by presenting information and results that can support evidence-based practice, ensuring the provision of good quality psychological services to the population. This is a way to "... contribute to the knowledge construction process and to the dissemination of scientific information that can provide guidance in the care offered to individuals in an effective and ethical manner" (Melnik, Souza, \& Carvalho, 2014, p.79). and Graduate Program in Health Sciences. 


\section{References}

Braveman, P., \& Barclay, C. (2009). Health disparities beginning in childhood: A life-course perspective. Pediatrics, 124(Suppl.3), S163. http://dx.doi.org/ 10.1542/peds.2009-1100D

Broering, C. V., \& Crepaldi, M. A. (2013). Psychological preparation for surgery: Verbal report of the drawingstory. Estudos de Psicologia (Campinas), 30(3), 367374. http://dx.doi.org/10.1590/S0103-166X2013 000300006

Camon, V. A. A. (1984). Psicologia hospitalar: a atuação da psicologia no contexto hospitalar. São Paulo: Traço.

Crepaldi, M. A., Linhares, M. B. M., \& Perosa, G. B. (2006). Temas em psicologia pediátrica. São Paulo: Casa do Psicólogo.

Crepaldi, M. A., Rabuske, M. M., \& Gabarra, L. M. (2006). Modalidades de atuação no psicólogo em psicologia pediátrica. In M. A. Crepaldi, M. B. M. Linhares, \& G. B. Perosa (Orgs.), Temas em psicologia pediátrica (pp.13-55). São Paulo: Casa do Psicólogo.

Dich, N., Hansen, A. M., Avlund, K., Lund, A. R., Mortensen, E. L., Bruunsgaard, H., \& Rod, N. H. (2015). Early life adversity potentiates the effects of later life stress on cumulative physiological dysregulation. Anxiety, Stress, \& Coping: An International Journal, 28(4), 372-390. http://dx.doi.org/10.1080/106158 06.2014 .969720

Kazak, A. E. (2006). Pediatric Psychosocial Preventative Health Model (PPPHM): Research, practice, and collaboration in pediatric family systems medicine. Families, Systems, \& Health, 24(4), 381-395. http:// dx.doi.org/10.1037/1091-7527.24.4.381

Kazak, A. E., Rourke, M. T., Alderfer, M. A., Pai, A., Reilly, A. F., \& Meadows, A. T. (2007). Evidence-based assessment, intervention and psychosocial care in pediatric oncology: A blueprint for comprehensive services across treatment. Journal of Pediatric Psychology, 32(9), 1099-1110. http://dx.doi.org/10.10 93/jpepsy/jsm031

Matarazzo, J. D. (1980). Behavioral health and behavioral medicine: Frontiers for a new healthy psychology. American Psychologist, 35(9), 807-817.
Melnik, T., Souza, W. F., \& Carvalho, M. R. (2014). A importância da prática da psicologia baseada em evidências: aspectos conceituais, níveis de evidência, mitos e resistências. Revista Costarricense de Psicología, 33(2), 79-92.

Miller, G. E., Chen, E., \& Parker, K. J. (2011). Psychological stress in childhood and susceptibility to the chronic diseases of aging: Moving towards a model of behavioral and biological mechanisms. Psychological Bulletin, 137(6), 959-997. http://dx.doi.org/10.1037/ a0024768

Robert, M. C., \& Steele, R. G. (2009). Handbook of pediatric psychology (4th ed.). New York: The Guilford Press.

Romano, B. W. (1990). A prática da psicologia nos hospitais. São Paulo: Pioneira Thomson Learning.

Rutter, M., \& Sroufe, L. A. (2000). Developmental psychopathology: Concepts and challenges. Development and Psychopathology, 12(3), 265-296.

Sameroff, A. (2010). A unified theory of development: A dialectic integration of nature and nurture. Child Development, 81(1), 6-22. http://dx.doi.org/10.1111/ j.1467-8624.2009.01378.x

Segerström, S. C. (2012). The Oxford handbook of psychoneuroimmunology. New York: Oxford University Press.

Shonkoff, J. P., Garner, A. S., The Committee on Psychosocial Aspects of Child and Family Health, Committee on Early Childhood, Adoption, and Dependent Care, and Section on Developmental and Behavioral Pediatrics. (2012). The lifelong effects of early childhood adversity and toxic stress. Pediatrics, 129(1), e232-246. http://dx.doi.org/10.1542/peds. 2011-2663

Slavich, G. M., \& Cole, S. W. (2013). The emerging field of human social genomics. Clinical Psychological Science, 1(3), 331-348. http://dx.doi.org/10.1177/ 2167702613478594

Winett, R. A., King, A., \& Altman, D. G. (1989). Health psychology and public health. São Paulo: Pergamon Press. 
